\title{
Discussion: Impact of Technology on Traditional Agriculture: The Peru Case
}

\author{
WOLFGANG F. STOLPER
}

Professor Coffey has presented a detailed and well-thought-out calculation of the transformation of traditional agriculture in a particular area, in which he has undertaken the necessary extensive fieldwork-a substantial achievement by itself. His conclusions are rather pessimistic. Given his assumption, it will be impossible to achieve the aim of the Alliance of Progress to raise incomes, even if the best presently known techniques are adopted. Moreover, half of the people are and remain redundant. The questions which this raises (some of which Professor Coffey raises himself in the extended version) are several.

The first one relates to the internal logic of the model. I do not mean that Professor Coffey has made a mistake, because, as far as I can tell, he hasn't. Nor am I competent to question the input coefficients which he found in his fieldwork. But, logically, any answer one finds must depend on the assumptions one makes. Specifically, the model places limitations on the speed with which land use can be changed and new methods introduced, and by which maximum annual yields can increase. These assumptions sound plausible; in fact, Professor Coffey believes that they err on the optimistic side. Given the assumptions, it is possible to double net returns per available "man equivalent" by the year 2000 , provided, one should perhaps add, that population and the labor force do not increase faster than in the past. If it were possible to reduce the available manpower to the required one, the increase could be about five and one-half times.

This is important information to the policy maker. Yet the policy maker must ask a few additional questions which relate to both the inputs and the outputs assumed in the model. On the output side, the model assumes no new products, but essentially deals with the problems of producing the old products (including improved versions, however) by better methods. This may be a most realistic assumption to make for the Cuzco Sierra region (about which, I repeat, I know nothing). But it seems to me to limit the applicability of the findings. In some important cases in Africa, which I know, the transformation of traditional agriculture has involved the introduction of new outputs and has then changed incomes rather dramatically. The introduction of cocoa into the (then) Gold Coast and Nigeria is an outstanding example, particularly as the industry was developed by indigenous peasants without plantation agriculture. Other examples are the

WolfGang F. StolPer is director of the Center for Research on Economic Development, University of Michigan. 
introduction of peanuts, rubber, and, most recently, rice in West Africa, and fruit trees and vegetables in North Africa. In all these cases, the transformation of traditional agriculture involved both improved methods for producing traditional goods-e.g., oil palm products or, more recently and still in an experimental stage, fisheries-and the introduction of new cash crops.

On the input side, the model allows for a great variety of purchased inputs to produce the improved but traditional outputs more efficiently. It does not allow for investments in, say, roads or storage facilities, or beefdrying facilities and the like, which would raise net returns through lowering input cost, raising ex-farm prices while lowering them simultaneously to the consumers. This is not meant as a criticism of the paper. Yet it raises necessary questions which a planner will want to have answered. Professor Coffey answers them implicitly by assuming constant prices for the outputs.

If there are no new alternative products, and if integrating the investigated area with the more developed parts of Peru does not lead to higher ex-farm prices and new possibilities (such as dried beef, or poultry), the outlook for the region is bleak indeed. It just is not a place that can be developed. Yet the policy makers in Lima will have to ask and answer the question, What can we do when more than half the population lives in an area with no visible future?

This leads me to my last point. Professor Coffey, in two footnotes to Table 1, assumes a 12-percent rate of interest on bank capital and a higher one for nonbank capital. Such levels of interest rates are commonly suggested in the literature on shadow pricing on grounds that they reflect the "true" marginal productivity or scarcity of capital better than the admittedly imperfect market rates. Yet, in practice, subsidized development banks make capital available at lower rates. And, as a theorist, I am by no means sure just why one should assume such a high "true" marginal productivity.

I have spelled out some of the reasons for my doubts in my book, Planning Without Facts (Harvard University Press, 1966). The relevant problem seems to me to be the following. Roughly half of what statisticians certify to be investments consist of such things as administrative buildings, schools, hospitals, etc., whose connection with any economic pay-off calculation is tenuous at best, and about which decisions are not made purely or even largely on economic grounds. (This does not, of course, mean that we economists abdicate and leave it all to the political process. But to discuss this issue would go beyond what is relevant here.) Now suppose, for argument's sake, that we eliminated all demand for capital which could not be defended on purely economic grounds. How many investments could be found at 12 percent? 10 percent? 6 percent? My Afri- 
can experience suggests: not too many; certainly not so many that something wouldn't be left for the type of investment I just assumed away. And my theoretical hunch suggests that this must be more generally true. For there is, as von Neumann has pointed out, some relation between the rate of growth and the rate of interest. If the marginal productivity of capital really is so high, why don't the underdeveloped countries grow faster?

If my hunch is right, then the alternative to spending money on Sierra agriculture is not so much the more efficient investments in fish meal or coastal agriculture as the more or less "social" investments (which are of course important) and the possibilities of opening up the Selva region, about which I know even less than the Peruvians themselves. If so, then the bleakness of the region's future is no reason for not doing all that one can do now, as long as also everything is being done to open up alternatives which have an economic return of, say, 7-8 percent. This is a conclusion which is also in basic agreement with Professor Coffey's own, as expressed in his extensive paper, which concludes that the prospects of the Sierra region depend on what happens elsewhere in the economy. Since everything depends on everything else in an interdependent economy, this is undoubtedly a sound conclusion. 